\title{
Using a technology-based intervention to promote weight loss in sedentary overweight or obese adults: a randomized controlled trial study design
}

\author{
This article was published in the following Dove Press journal: \\ Diabetes, Metabolic Syndrome and Obesity:Targets and Therapy \\ 3 February 2011 \\ Number of times this article has been viewed
}

\author{
Vaughn W Barry' \\ Amanda C McClain' \\ Sara Shuger ${ }^{\prime}$ \\ Xuemei Sui ${ }^{\prime}$ \\ James W Hardin ${ }^{2}$ \\ Gregory A Hand' \\ Sara Wilcox' \\ Steven N Blair ${ }^{1,2}$ \\ 'Department of Exercise Science; \\ ${ }^{2}$ Department of Epidemiology and \\ Biostatistics, University of South \\ Carolina, Columbia, SC, USA
}

Correspondence: Vaughn W Barry Department of Exercise Science, Public Health Research Center, University of South Carolina, 921 Assembly Street, Columbia, SC 29063, USA

Tel + I 8037777566

Fax + I 8037772504

Email barryvw@email.sc.edu
Purpose: The SenseWear ${ }^{\mathrm{TM}}$ Armband is an activity monitor developed to improve lifestyle self-monitoring. Currently, few studies assess electronic self-monitoring and weight loss with a lifestyle intervention program. To our knowledge, only one study has used the SenseWear Armband in combination with a lifestyle intervention to improve weight loss, and no studies have evaluated whether a self-monitoring intervention based solely on the armband can promote weight loss. Consequently, the aims of the study were to assess weight loss from electronic self-monitoring, to compare these values to the lifestyle intervention and standard care groups, and to compare weight loss with lifestyle intervention with and without the armband.

Patients and methods: We recruited 197 sedentary overweight or obese adults (age, $46.8 \pm 10.8$ years; BMI, $33.3 \pm 5.2 \mathrm{~kg} / \mathrm{m}^{2}$ ) to participate in the 9-month study. Participants were randomized into one of four weight loss groups: 1) the standard care group received a selfdirected weight loss program, complete with an evidence-based weight loss manual (standard care, $\mathrm{n}=50$ ); 2) a 14-week group-based behavioral weight loss program followed by weekly, biweekly, and monthly telephone counseling calls (GWL, $n=49) ; 3$ ) the use of the armband to help improve lifestyle self-monitoring (SWA alone, $n=49$ ); or (4) the group-based behavioral weight loss program and follow-up telephone counseling calls plus the armband (GWL + SWA, $n=49$ ). All participants received the evidence-based weight loss manual at baseline. All measures were performed at baseline and months 4 and 9 . The primary outcomes were weight loss and waist circumference reduction.

Results: This study is a well-designed randomized controlled study powered to detect a $0.5-\mathrm{kg}$ weight loss and $0.6-\mathrm{cm}$ waist circumference reduction in overweight and obese sedentary adults.

Conclusion: Innovative technologies are providing lifestyle self-monitoring and weight loss tools. Utilizing these technologies may be an important step in improving the current obesity epidemic.

Keywords: lifestyle, energy balance, behavioral education, accelerometer, SenseWear ${ }^{\mathrm{TM}}$ Armband

\section{Introduction}

Approximately two-thirds of adults in the United States are overweight or obese. ${ }^{1}$ Excess weight is associated with many health conditions, including hypertension, dyslipidemia, type 2 diabetes mellitus, osteoarthritis, cardiovascular disease, stroke, and some cancers. ${ }^{2-4}$ Furthermore, the medical cost of excess weight for the United States 
is estimated to be $\$ 147$ billion per year. ${ }^{5}$ Clearly, effective weight loss solutions are needed to improve the country's health profile.

One strategy that has been proven effective for weight loss, at least in the short term, is group-based lifestyle intervention weight loss programs (GWL). ${ }^{6}$ These programs target key features in weight loss, including healthy eating, increased physical activity, and behavioral therapy. Behavioral therapy incorporates behavior change strategies such as dietary and physical activity self-monitoring, goal setting, problem solving, and stress management, and many of these programs are grounded in behavioral science theory, including Social Cognitive Theory and the Transtheoretical Model. ${ }^{7}$ Individuals who effectively incorporate these key features may reduce their initial body weight by $8 \%-10 \%$ within 4-6 months of treatment. ${ }^{8}$ Unfortunately, there are limitations in using GWLs to reach large segments of the population efficiently and cost effectively, such as obtaining qualified staff, participant availability, and the need for smaller group sizes.

The use of physical activity monitoring devices, such as pedometers and accelerometers, helps individuals increase their physical activity through self-monitoring, goal setting, and other behavioral strategies. Although these devices effectively encourage participants to increase their physical activity habits, ${ }^{9}$ they only marginally reduce weight when used alone. ${ }^{10}$ Both physical activity and energy intake selfmonitoring are needed for more effective weight loss. ${ }^{11,12}$ The SenseWear ${ }^{\mathrm{TM}}$ Armband (BodyMedia, Pittsburgh, PA, USA) is a physical activity monitor that includes software for selfmonitoring of daily energy expenditure and energy intake. The real-time feedback of these parameters can improve individual self-monitoring and therefore may improve weight loss outcomes.

Research has shown that the armband is accurate when measuring resting energy expenditure ${ }^{13-15}$ and when measuring energy expenditure in laboratory ${ }^{13,15,16}$ (ie, treadmill and cycle ergometry exercise) and free-living conditions. ${ }^{17,18}$ Therefore, the armband may be an appropriate device in assessing energy expenditure for weight loss or weight maintenance purposes. In one recent study, the armband was used as a real-time self-monitoring device in conjunction with a GWL. This small study $(\mathrm{n}=57)$ reported improved weight loss over 3 months when the armband was worn in conjunction with a GWL, beyond which weight loss was accomplished with a GWL alone. ${ }^{19}$ This small study did not include an armband-alone group and did not utilize a nonGWL control group. The purpose of the Lifestyle Education for Activity and Nutrition (LEAN) randomized controlled trial is 1) to assess a self-monitoring strategy for physical activity and diet in conjunction with GWL to promote weight loss and waist circumference reduction compared with a standard care intervention and a standard GWL without self-monitoring and 2) to assess weight loss and waist circumference reduction when using self-monitoring alone.

\section{Methods}

We performed a 9-month randomized controlled trial in which we randomly assigned underactive overweight and obese men and women to one of four weight loss groups. Three of the four groups received a standard GWL or armband, or both. All four groups received a weight loss manual. Outcome measures were assessed during a baseline assessment and again at 4 and 9 months. The primary outcomes of the study were weight loss and waist circumference reduction.

\section{Description and selection criteria of participants}

All participants were recruited from the greater Columbia, South Carolina area, via flyers, newspaper ads, newsletters, emails, health fairs, and word of mouth. LEAN study staff recruited underactive men and women aged between 18 and 65 years who were overweight or obese (body mass index [BMI] of $25-45 \mathrm{~kg} / \mathrm{m}^{2}$ ) and had access to the Internet (needed for armband use). Participants were considered underactive if they completed $<150$ min of moderate to vigorous physical activity throughout the week in bouts $>10 \mathrm{~min}$. The inclusion and exclusion criteria for LEAN are shown in Table 1.

\section{Participant screening}

All LEAN study participants progressed through the study, as outlined in Figure 1, beginning with an initial contact and eligibility assessment via telephone interview. Potential participants were asked general eligibility questions regarding their age, height, weight, Internet access, medical history, and physical activity level. Medical history and physical activity-related questions were asked to assess the participants' current physical activity level and ability to exercise. All eligible participants willing to learn more about the study were invited to an orientation session.

At the orientation session, potential participants received an explanation regarding the purpose of the study and study expectations. This discussion included the participant responsibilities and potential health benefits and risks related to study participation. All interested participants signed an informed consent approved by the University of 
Table I Inclusion and exclusion criteria for LEAN

\begin{tabular}{|c|c|}
\hline \multicolumn{2}{|l|}{ Inclusion criteria } \\
\hline Age & $18-65$ years \\
\hline \multirow[t]{2}{*}{ Physically inactive } & Participants must be physically inactive \\
\hline & $\begin{array}{l}\text { - Not accumulating } 150 \mathrm{~min} \text { of moderate to vigorous physical activity throughout the week } \\
\text { in bouts } \geq 10 \mathrm{~min}\end{array}$ \\
\hline BMI & $25-45 \mathrm{~kg} / \mathrm{m}^{2}$; height and weight measured and BMl calculated at the orientation session \\
\hline Internet access & This access could be at work and/or at home \\
\hline Informed consent & $\begin{array}{l}\text { Must be capable and willing to give written informed consent, understand exclusion criteria, } \\
\text { and accept the randomized group assignment }\end{array}$ \\
\hline \multicolumn{2}{|l|}{ Exclusion criteria } \\
\hline Physical activity & $\begin{array}{l}\text { Physical ailments that limit physical activity } \\
\text { - Heart condition } \\
\text { - Pain in chest or legs during physical activity } \\
\text { - Serious bone or joint problems } \\
\text { - Difficulty walking or being physically active }\end{array}$ \\
\hline Significant weight loss & Lost $>20 \mathrm{lbs}$ in the last 6 months \\
\hline Pregnancy & Currently pregnant or planning to become pregnant in the next year \\
\hline Blood pressure & $\begin{array}{l}\geq 160 / 95 \mathrm{~mm} \mathrm{Hg} \text {; confirmed at two separate sessions } \\
\text { - Participant is included if they see their physician and a lower blood pressure is measured on } \\
\text { two separate occasions }\end{array}$ \\
\hline $\begin{array}{l}\text { Participating in a formal exercise } \\
\text { or weight loss program }\end{array}$ & Examples include Jenny Craig or Weight Watchers \\
\hline Medical history & $\begin{array}{l}\text { - Surgery of any type in the last year (if stayed overnight or longer) } \\
\text { - Surgery to lose weight } \\
\text { - Hospitalized in the last year (if stayed overnight or longer) } \\
\text { - Personal illnesses: } \\
\text { - Heart attack or angina (if in the last year) } \\
\text { - Congestive heart failure (if in the last year) } \\
\text { - Stroke (if in the last year) } \\
\text { - Eating disorders } \\
\text { - Uncontrolled hypo- or hyperthyroidism } \\
\text { - Diabetes: type I; type } 2 \text { (not controlled; see medications) } \\
\text { - Cancer: melanoma and others (within last } 5 \text { years) } \\
\text { - HIV infection } \\
\text { - And other illnesses that may affect study outcomes }\end{array}$ \\
\hline Medications & $\begin{array}{l}\text { That may affect weight loss as determined by the study physician } \\
\text { - This includes any insulin (except long-acting insulin) }\end{array}$ \\
\hline Alcohol & $>14$ drinks/week or $>60$ drinks/month \\
\hline Depression & Score $\geq 16$ on the CES-D questionnaire \\
\hline Travel & Planning to be out of town $>4$ weeks out of the next 9 months \\
\hline
\end{tabular}

Abbreviations: BMI, body mass index; CES-D, Center for Epidemiologic Studies Depression Scale; LEAN, Lifestyle Education for Activity and Nutrition.

South Carolina's Internal Review Board and completed a one-on-one medical screening interview with study staff. Some participants were deemed temporarily ineligible until they received medical clearance from the study medical director. All eligible participants were scheduled to take part in a run-in period.

During the run-in period, participants were asked to keep a 7-day food diary and invited back to a session in which they returned the diary, completed several questionnaires, and had their blood pressure assessed after a 5-min rest. During this session, each participant received the armband with oral and written instructions for proper wear. Participants were given the opportunity to wear and adjust the armband.
During the session, participants were encouraged to ask questions, particularly questions regarding the armband. At the conclusion of this session, participants were asked to wear the armband for 7 days to assess baseline physical activity levels and concurrently complete an additional 7-day food diary. Participants received no feedback from the armband during this period. Both the armband and food diary were returned during their next visit, the baseline assessment. Few participants were asked to perform the food and physical activity assessments an additional time due to lack of adherence. Participants who successfully completed 7-day food diaries and also wore the armband were eligible to continue. The run-in activities were included in the study 


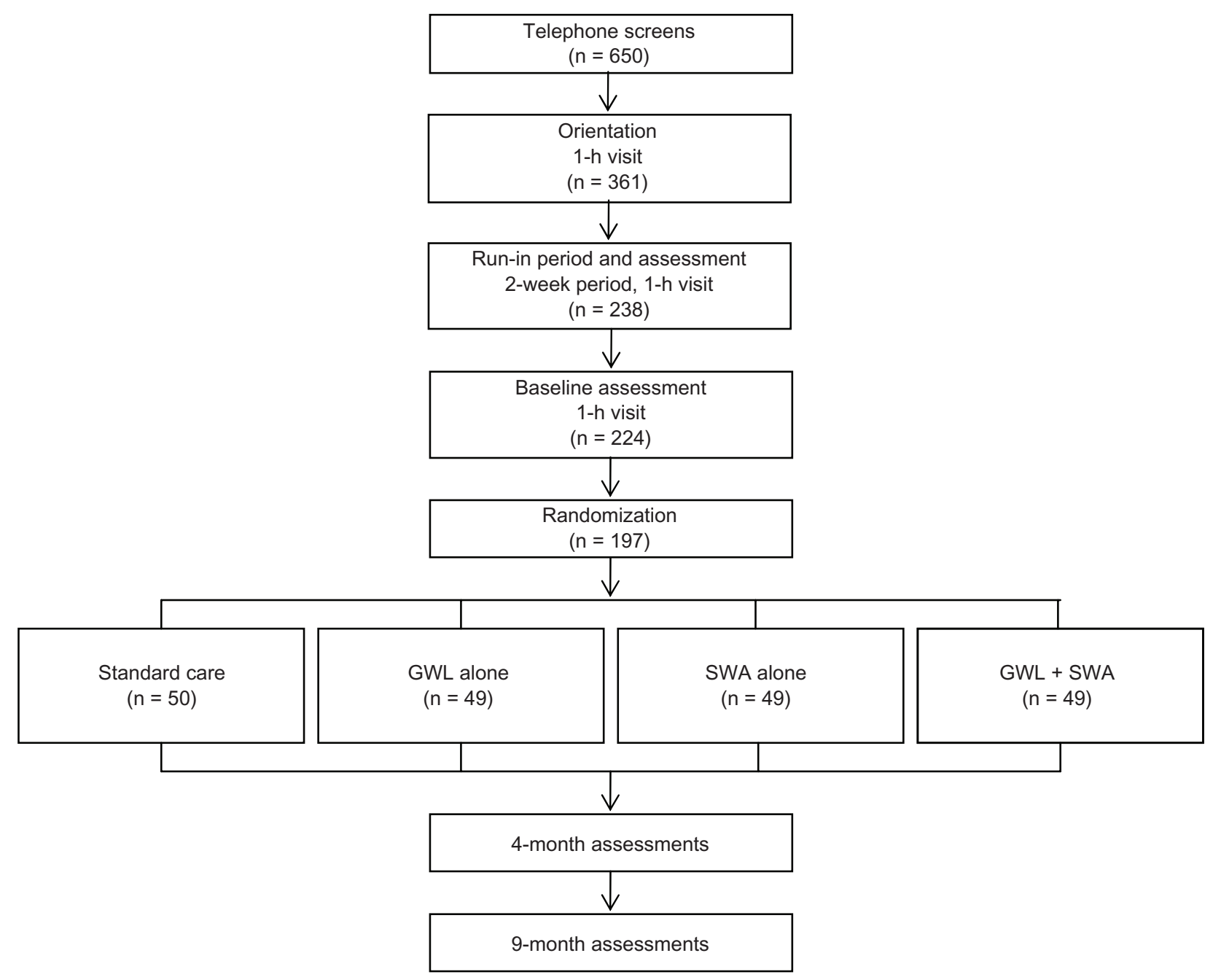

Figure I Participant flow from screening to randomization. The standard care group received a manual containing weight loss information. The GWL-alone group received a group-based lifestyle intervention weight loss program. The SWA-alone group received only the armband. The GWL + SWA group received the group-based lifestyle intervention weight loss program plus SWA.

Abbreviations: GWL, group-based behavioral weight loss program group; SWA, self-monitoring with armband group.

flow for two reasons. First, keeping a food diary and wearing an armband allowed participants to better understand what type of activities would be required in the study. The goal was to screen out participants who were unlikely to adhere to study requirements. By doing this, baseline measures were performed on participants who were more likely to be randomized and adhere to the study protocol. The second reason for including the run-in period and session was to reduce the participant questionnaire burden at the orientation and baseline assessments by spreading them across multiple visits.

The baseline assessment was held at least 7 days after the run-in session. Participants were asked to fast at least $7 \mathrm{~h}$ prior to this session. At this session, participants returned the armband and the 7-day food diary. During the session, participants completed standardized measurements including, height, weight, resting blood pressure, resting heart rate, skinfold measurements, and a blood draw, and returned questionnaires that were mailed to them prior to the assessment. A final inclusion/exclusion screening was performed on all participants prior to the randomization session.

\section{Randomization}

After successfully completing all screening visits (orientation, run-in, and baseline assessment) and run-in activities and signing the informed consent, eligible participants were randomized into one of the four groups. These groups include the standard care group (standard care), which received an evidence-based weight loss manual that was also distributed to the other three groups; the GWL-alone group (GWL), the armband-alone group (SWA alone), and the combined GWL and armband group (GWL + SWA). The randomization 
process was performed by the study statistician based on a computer-automated randomization sequence. The sequence was determined from randomly permuted blocks of equal length with each having a fixed number of treatment allotments to balance the treatment enrollments over time. Although randomization theoretically leads to an equality of all factors in both intervention and standard care groups, we employed a stratification procedure to ensure equal numbers of participants with specific and potentially confounding characteristics in all four groups. Randomization was stratified based on age, sex, baseline BMI, and availability to attend the GWL sessions.

During the randomization visit, all participants received the evidence-based weight loss manual, an envelope containing their randomization assignment, and a brief health education session with handouts that covered physical activity, healthy eating, and weight loss. The physical activity education provided an overview of what constitutes physical activity, physical activity benefits, different types of physical activity, current physical activity recommendations, tips for starting physical activity, and warning signs and symptoms for heart attack and stroke. Healthy eating education included the benefits of healthy eating, the five themes of MyPyramid, ${ }^{20}$ the six food groups of MyPyramid, a discussion of portion control, and a serving size guide. Weight loss education covered overweight and obesity risks, BMI, safe rates of weight loss, energy balance, and solutions for common weight loss challenges. All participants were also reminded of study expectations for the group to which they were assigned. Participants randomized to SWA alone received a 90-min training session on how to use the armband and corresponding website.

As shown in Table 2, the randomization process achieved a reasonable balance across the four arms at baseline. The only variable found to differ in the four arms at baseline was triglycerides, and these differences were modest. The majority of participants in this sample were obese, educated, nonsmoking women. On average, study participants had

Table 2 Baseline characteristics

\begin{tabular}{|c|c|c|c|c|c|}
\hline Characteristics & $\begin{array}{l}\text { Total } \\
(n=197) \\
(\text { mean (SD), } \\
\text { N (\%) or median } \\
(25 Q-75 Q))\end{array}$ & $\begin{array}{l}\text { Standard care } \\
(n=50) \\
(\text { mean (SD), } \\
\text { N (\%) or median } \\
(25 Q-75 Q))\end{array}$ & $\begin{array}{l}\text { GWL } \\
(n=49) \\
\text { (mean (SD), } \\
\text { N (\%) or median } \\
(25 Q-75 Q))\end{array}$ & $\begin{array}{l}\text { SWA alone } \\
(n=49) \\
(\text { mean (SD), } \\
\text { N (\%) or median } \\
(25 Q-75 Q))\end{array}$ & $\begin{array}{l}\text { GWL + SWA } \\
(n=49) \\
\text { (mean (SD), } \\
\text { N (\%) or median } \\
(25 Q-75 Q))\end{array}$ \\
\hline Age (years) & $46.9(10.8)$ & $47.2(8.9)$ & $46.8(12.4)$ & 47.7 ( I I.6) & $45.7(10.4)$ \\
\hline Female (\%) & $161.0(81.7)$ & $42.0(84.0)$ & $39.0(79.6)$ & $40.0(81.6)$ & $40.0(81.6)$ \\
\hline Weight (kg) & $92.8(18.4)$ & $94.2(18.2)$ & $93.2(18.6)$ & $92.0(21.0)$ & $91.9(15.7)$ \\
\hline \multicolumn{6}{|l|}{ Waist circumference } \\
\hline Male (total $n=36$ ) & $110.6(12.6)$ & II3.9 (I2.2) & $105.7(8.7)$ & II 5.5 (I4.6) & $108.2(13.5)$ \\
\hline Female $($ total $n=161)$ & $97.3(13.1)$ & $97.5(11.8)$ & $100.0(13.7)$ & $94.7(13.0)$ & $96.8(13.7)$ \\
\hline Body mass index $\left(\mathrm{kg} / \mathrm{m}^{2}\right)$ & $33.3(5.2)$ & $33.7(5.5)$ & $33.1(4.8)$ & $33.2(5.4)$ & $33.0(5.0)$ \\
\hline$\%$ Body fat & $38.4(5.3)$ & $38.9(4.7)$ & $38.1(5.8)$ & $38.3(5.3)$ & $38.1(5.3)$ \\
\hline \multicolumn{6}{|l|}{ Blood pressure (mm Hg) } \\
\hline Systolic & $126.0(12.0)$ & $127.0(13.0)$ & $126.0(11.0)$ & $128.0(13.0)$ & $124.0(11.0)$ \\
\hline Diastolic & $80.0(8.0)$ & $81.0(9.0)$ & $79.0(8.0)$ & $81.0(9.0)$ & $79.0(7.0)$ \\
\hline \multicolumn{6}{|l|}{ Fasting plasma lipids $(\mathrm{mg} / \mathrm{dL})(\mathrm{n}=164)$} \\
\hline Total cholesterol & $173.3(44.2)$ & I7I.8 (34.2) & $170.8(48.3)$ & |78.| (47.5) & $172.5(46.1)$ \\
\hline LDL cholesterol & $105.5(42.5)$ & $102.5(33.0)$ & $103.2(46.2)$ & I I I.2 (45.2) & $105.2(44.8)$ \\
\hline HDL cholesterol & $47.8(19.4)$ & $48.5(20.3)$ & $47.5(18.8)$ & $45.4(19.5)$ & $50.2(19.4)$ \\
\hline Triglycerides (median (25Q-75Q)) & $77.8(56.8-128.2)$ & $78.45(59.8-139.9)$ & $77.4(54.5-132.7)$ & $88.2(57.6-129.8)$ & $72.1(54.3-103.7)$ \\
\hline $\begin{array}{l}\text { Fasting blood glucose }(\mathrm{mg} / \mathrm{dL}) \\
(\mathrm{n}=164)\end{array}$ & $97.7(24.8)$ & 99.1 (18.3) & $104.0(29.6)$ & $98.0(21.9)$ & $88.8(26.0)$ \\
\hline College degree, 4 years (\%) & $152.0(77.2)$ & $37.0(74.0)$ & $40.0(81.6)$ & $39.0(79.6)$ & $36.0(73.5)$ \\
\hline Current smoker (\%) & $10.0(5.0)$ & $5.0(10.0)$ & $1.0(2.0)$ & $2.0(4.0)$ & $2.0(4.0)$ \\
\hline \multicolumn{6}{|l|}{ Race $(\%)$} \\
\hline White & $131.0(66.8)$ & $30.0(60.0)$ & $33.0(68.8)$ & $33.0(67.4)$ & $35.0(71.4)$ \\
\hline Black & $63.0(32.1)$ & $19.0(38.0)$ & $14.0(29.2)$ & $16.0(32.7)$ & $14.0(28.6)$ \\
\hline Other & $2.0(1.0)$ & $1.0(2.0)$ & $1.0(2.1)$ & $0.0(0.0)$ & $0.0(0.0)$ \\
\hline
\end{tabular}

Notes: The standard care group received a manual containing weight loss information, the GWL group received a group-based behavior weight loss program, the SWA-alone group received the armband, and the GWL + SWA group received the group-based behavior weight loss program plus the armband.

Abbreviations: GWL, group-based behavioral weight loss program group; HDL, high-density lipoprotein; LDL, low-density lipoprotein; SD, standard deviation; SWA, self-monitoring with armband group. 
blood pressures, fasting plasma lipid profiles, and fasting blood glucose levels within normal ranges.

\section{Follow-up examinations}

Follow-up data collection visits occurred at 4 and 9 months after randomization. The same measurements and questionnaires completed during the baseline session were assessed during each follow-up visit with only one exception. This one exception was armband wear during the month 4 assessment. Participants who were not randomized to wear the armband (ie, GWL and standard care) were asked to wear the armband for 7 days following the month 4 assessment without receiving physical activity or energy balance feedback from the SenseWear website. Participants already assigned to wear the armband (ie, GWL + SWA and SWA alone) continued to wear the monitor with full access to the SenseWear platform. During the baseline and month 9 assessments, no participants received physical activity and energy balance feedback from the SenseWear platform.

\section{Outcome measures and methods}

Primary outcome measures are weight loss and waist circumference reduction. Secondary outcome measures include daily energy expenditure in physical activity, daily caloric intake, percent of participants losing $\geq 5 \%$ of baseline body weight, and stages of motivational readiness for physical activity and diet changes. Tertiary outcomes are blood pressure, fasting lipid profile (ie, low-density lipoprotein, high-density lipoprotein, and total cholesterol), fasting blood glucose, fasting blood insulin, and quality of life. The exploratory variables include heart rate variability. All the outcome measures were obtained during the baseline, month 4, and month 9 assessments.

\section{Anthropometric and physiological measures}

All participants were asked to complete baseline, 4-month, and 9-month assessment visits. During these sessions, several measures were obtained, including height, weight, waist circumference, resting blood pressure, resting heart rate, and gender-specific three-site skinfolds. All variables were measured three consecutive times to improve measurement accuracy. Height and weight were assessed without shoes using a wall-mounted stadiometer and a balance beam scale. The same measuring tape with tension rod was used for each waist circumference measure. This measure was assessed with the measuring tape being placed just above both iliac crests. Supine blood pressures and heart rates were measured alternately after a 5-min supine resting period. Blood pressures were measured using calibrated mercury sphygmomanometers and a supine version of the Seventh Report of the Joint National Committee on Prevention, Detection, Evaluation, and Treatment of High Blood Pressure protocol. ${ }^{21}$ Heart rates were multiplied by two after palpating the radial artery for $30 \mathrm{sec}$. Standardized genderspecific three-site skinfolds were used to assess percent body fat. $^{22}$ The male skinfold sites were the chest, abdomen, and thigh. The female skinfold sites were the triceps, suprailiac, and thigh. The same calipers were calibrated prior to each session. The body densities and percent body fats were calculated using the American College of Sports Medicine's gender-specific equations ${ }^{22}$ followed by the Siri equation. ${ }^{23}$ All LEAN study staff were trained by the same staff member, in order to minimize intertechnician variability. Fasting blood draws took place during the baseline, 4-month, and 9-month assessments. All blood draws occurred between 7:00 a.m. and 9:30 a.m. and were taken from the antecubital vein. Participants who were not fasting completed the blood draw at a later time.

\section{Physical activity assessment}

Physical activity levels were assessed using the armband. The armband is a commercially available (www.bodymedia. com) lightweight physical activity monitor that is worn on the upper left arm halfway between the acromion and olecranon processes. This device measures physical activity using triaccelerometry technology augmented by two heat sensors (a thermistor-based skin surface sensor and a proprietary heat flux sensor) and a galvanic skin response sensor. These four internal sensors turn on the monitor (ie, with skin contact) and estimate armband compliance, daily energy expenditure, step count, sleep efficiency, and the intensity, duration, and frequency of physical activity bouts. Collected physical activity data were downloaded by LEAN study staff during the baseline, 4-month (GWL and standard care groups only), and 9-month assessments. During the 4-month assessment, groups already wearing the armband (GWL + SWA and SWA alone) continued to wear and download their physical activity data without staff involvement. All armband data were analyzed by computer-based software using demographic information (ie, gender, age, height, and weight at prior assessment) and proprietary algorithms. Throughout the study, the GWL + SWA and SWA-alone group participants used the self-monitoring device to aid behavior change via real-time lifestyle feedback targeting physical activity and dietary tracking. 


\section{SenseWear Armband validity}

Validity of armband energy expenditure estimates has been reported in several conditions, including resting, exercise (ie, treadmill and cycle ergometry), and free-living conditions (ie, physical activity and exercise). ${ }^{13-15,17,18}$ Free-living energy expenditure validity in the armband is accurate..$^{17,18}$ By comparing the armband with doubly labeled water, St-Onge et al found that daily energy expenditure was similar between the two methods with an interclass correlation of $0.81(P<0.01) .{ }^{17}$ Welk et al showed equivalent results when comparing the armband with the Intelligent Device for Estimating Energy Expenditure and Activity (IDEEA). ${ }^{18}$ The IDEEA is a portable physical activity monitor complete with a processing and storage unit, which clips to the hip. A total of five sensors are taped to the chest, thighs, and soles of the feet. This monitor can accurately assess basic body movements, including the type, onset, duration, and intensity of activity to $98 \%$ accuracy ${ }^{24}$ When compared with indirect calorimetry, the IDEEA monitor was $99 \%$ accurate. ${ }^{25}$ When Welk et al compared the armband with the IDEEA monitor, they found an average correlation of $0.82 \pm 0.06 .^{18}$

\section{Intervention}

\section{Theoretical framework}

The GWL and the weight loss manual were adapted from two evidence-based behavior change programs, Active Living Every Day (ALED) ${ }^{26}$ and Healthy Eating Every Day (HEED) ${ }^{27}$ to address weight loss through cognitive and behavioral skill building. Social Cognitive Theory ${ }^{28}$ and the Transtheoretical Model ${ }^{29}$ served as the theoretical frameworks for both programs. Social Cognitive Theory includes the constructs of self-regulation, self-efficacy, and expectancies, ${ }^{30}$ which were incorporated into ALED and HEED lesson plans through weighing barriers and benefits of changing habits, setting goals and rewards, anticipating and planning for high-risk situations, and promoting small changes. The five cognitive strategies and five behavioral strategies in the Transtheoretical Model encouraged people to move from lower levels to higher levels of motivational readiness to change. ${ }^{31} \mathrm{~A}$ detailed description of the strategies applied in ALED and HEED has been published elsewhere. ${ }^{32-34}$

\section{Standard care}

The standard care group received a self-directed weight loss manual composed of cognitive and behavior change principles and learning activities based on the two evidencebased programs mentioned earlier, ALED ${ }^{26}$ and HEED. ${ }^{27}$
The manual focused on helping individuals use these cognitive and behavioral strategies (eg, goal setting, selfmonitoring, and habit formation) to adopt a more healthful eating pattern and to increase physical activity for weight loss. All four weight loss groups received this manual.

\section{Group-based behavioral weight loss program}

The GWL group participated in 14 GWL sessions administered during the first 4 months of the intervention. The first 12 sessions were held weekly, and sessions 13 and 14 occurred biweekly. The GWL sessions lasted $\sim 90 \mathrm{~min}$ No makeup sessions were offered, but participants who missed a session were mailed or emailed missed materials within 2 days of the missed session. Each GWL session corresponded to a chapter in the weight loss manual (Table 3). The group facilitators were trained and certified for ALED and HEED before the study groups began. Each GWL session was led by at least one facilitator. Individual GWL sessions followed the format outlined by the ALED ${ }^{26}$ and HEED ${ }^{27}$ curriculum, with the addition of a weekly weigh-in. The GWL session format was as follows: weigh-in, check-in, facilitated discussion, announcement of homework assignment, preview of the next session, summary of current session, and administration of an evaluation.

Before each GWL session, the participants' weights were recorded by the group facilitator. Participants then received a door prize, incentive, or food-tasting sample to encourage on-time arrival, weekly attendance, or opportunities to sample healthy snacks, respectively. Every group session started with a 15-20-min check-in that included a review of the previous week's homework assignment and participant experiences, followed by a facilitated discussion and learning activities. Homework assignments enabled achievement of skills learned in the session through individual practice at home. After a brief preview of the next session and a review of the current session, the group facilitator administered an evaluation to each participant that captured each participant's likes and dislikes of the individual session, opinions about the pace of the session, and ratings of the facilitator in four areas. The evaluation was administered, at a minimum, during the first four sessions, two midpoint sessions, and at the final session. Each evaluation was anonymous. Between GWL sessions, the interventionist reviewed all food and activity logs and homework returned during the previous session, provided written encouragement and feedback, and returned the logs and homework to participants during the following session. 
Table 3 Group-based behavioral weight loss program outline

\begin{tabular}{|c|c|c|c|}
\hline Session number & Chapter & Topic & Learning objectives \\
\hline I & I & Getting Off to a Healthy Start & $\begin{array}{l}\text { Participant introductions, program and session overview, weight } \\
\text { loss basics, stages of readiness to change introduction }\end{array}$ \\
\hline 2 & 2 & The A, B, C's of Healthy Eating & $\begin{array}{l}\text { Smart food choices, dietary balance and moderation, serving sizes } \\
\text { vs portions, reading food labels, stages of change assessment for } \\
\text { healthy eating }\end{array}$ \\
\hline 3 & 3 & Physical Activity is More Than Exercise & $\begin{array}{l}\text { Definitions of physical activity, exercise, and fitness; physical } \\
\text { activity benefits, recommendations, and intensity; caloric } \\
\text { expenditure; personal time study; getting started; stage of change } \\
\text { assessment for physical activity }\end{array}$ \\
\hline 4 & 4 & Weight in the Balance & $\begin{array}{l}\text { Energy balance, factors that affect weight loss, estimated resting } \\
\text { energy expenditure and daily calorie needs calculations, energy } \\
\text { density vs nutrient density, increasing weekly calorie burn, fad } \\
\text { diets, and dietary supplements }\end{array}$ \\
\hline
\end{tabular}
$4 b(G W L+$ SWA only)
5
5
SenseWear Platform Training
On the Right Track: Self-Monitoring

$\begin{array}{lll}6 & 6 & \text { Setting Goals for Weight Loss } \\ 7 & 7 & \text { I Know It's Good for Me, But ... }\end{array}$

8

9

10

II

12

13

14
8

9

10

II

12 and 13

14

14
Simple Ways to a Healthy Weight

Breaking the Habit: Taking Control of Triggers

Plan Ahead for Success

Identifying Sources and Asking for Help

What's Eating You? Managing Stress; Managing Your Time

Lifelong HEALTH!

Lifelong HEALTH!
Role of self-monitoring in losing weight, step counter/armband for self-monitoring physical activity, guidelines for self-monitoring nutrition and physical activity, completing the Lifestyle Summary Form, tracking thoughts

Elements and role of goal setting, realistic and safe weight loss goals

Review food and activity logs, personal benefits and barriers, IDEEA method for problem solving, stage of readiness to change assessment for physical activity and healthy eating

Evaluating the eating and physical activity environment, strategies for healthy eating when dining out, role of convenience foods, preparing food at home, identifying healthy alternatives

Internal and external triggers, physical hunger vs psychological hunger, planning healthy cues and triggers, coping with negative triggers, all foods can fit

Introduction to concept of lapse and relapse, identifying negative thoughts and their sources, strategies to change negative thoughts to positive thoughts, planning ahead for high-risk situations

Importance of social support, identifying kinds of support and who to ask, rewarding people that provide social support, dealing with unsupportive people

Cite personal values and compare with typical weekly activities, plan healthy eating and physical activity strategies for I week, stress and health, strategies for reducing stress

Lifestyle change confidence assessment, helpful strategies to boost confidence and facilitate further change, recognizing successes, preventing and preparing for potential lapses, adding variety to prevent boredom

Shared meal, reviewing barriers and benefits, reviewing progress toward healthy eating, setting new goals, stage of readiness to change assessment for healthy eating and physical activity, program major message summary, schedule first telephone follow-up call

Abbreviations: GWL, group-based behavioral weight loss program group; IDEEA, Intelligent Device for Estimating Energy Expenditure and Activity; SWA, self-monitoring with armband group.

After completing the 14 GWL sessions, participants received one-on-one telephone counseling with the interventionist to enhance maintenance of behavior change. Participants were asked to complete a total of six telephone calls with the interventionist over 5 remaining months the participants were in the program. The first two calls occurred every 2 weeks during the first month, and the last four calls occurred once a month for the remaining 4 months. The interventionist followed a specific protocol for each call: 1) reviewed participant's file and prepared for call prior 
to contact; 2) greeted participant and affirmed appointment time; 3) assessed physical activity and nutrition behaviors and compared with personal goals; 4) assessed physical activity and nutrition self-monitoring behaviors; 5) counseled participants on one or more physical activity and nutrition counseling topic areas based on the participant's stage of readiness to change; 6) reviewed goals and set new goals, if necessary; 7) assessed current weight and compared with weight goal; 8) reviewed weight goal and set a new goal, if necessary; and 9) scheduled next follow-up counseling call.

Using the Transtheoretical Model as a framework for counseling, the interventionist assisted participants in maintaining healthy changes and continuing to make more behavior changes. Counseling topic areas were a combination of behavioral change strategies, processes of change for the Transtheoretical Model, and extensions of the skills taught during the GWL sessions: pros/cons, increasing knowledge, barriers/benefits, motivation, self-monitoring, goal setting/ rewards, problem solving, planning, triggers/cues/environment, successes, personal thoughts, social support, stress/time management, self-efficacy, and relapse prevention.

\section{SWA alone}

Participants randomized to the SWA-alone group received a LEAN Participant SenseWear Armband handbook and the SenseWear platform, which consisted of the armband, a realtime display device, and a personalized Weight Management Solutions (WMS) Web account protected by a login and password. All group participants were asked to wear the armband at least $16 \mathrm{~h}$ during normal waking hours, to upload the armband daily to their WMS accounts, and to enter food intake and weight daily into their WMS accounts for the duration of the intervention. Each SWA-alone participant completed a facilitator-mediated SenseWear platform training with individual access to the Internet lasting $\sim 90 \mathrm{~min}$. These participants then scheduled a follow-up call with the interventionist for the following week. The follow-up call allowed participants to ask questions related to the SenseWear platform and permitted the interventionist to document that the participant was successful in logging in to the WMS account, uploading the armband, and inputting food and weight data into the WMS account. Except for questions regarding armband use, the SWA-alone participants received limited contact from study staff.

\section{GWL + SWA}

Individuals randomized to this group participated in the 14 GWL sessions (separate from the GWL group) and six telephone follow-up calls and wore the armband. One addi- tional GWL session (Table 3, session 4b) was included at week 5 to provide training for the armband prior to covering materials on self-monitoring. Due to feasibility and distinct differences in the level of contact with the interventionist, the GWL + SWA and SWA-alone groups received slightly different intensities in SenseWear platform training. Group SWA-alone participants received the training in small groups (no more than three participants) and had individual Internet access from a laptop. Group GWL + SWA participants received the training during session $4 \mathrm{~b}$ and did not have individual access to the Internet.

The major principle behind using the armband for both the GWL + SWA and SWA-alone groups was feedback from the real-time display device. This real-time display allowed participants to concurrently track total calories burned, minutes spent performing physical activity, and number of steps taken throughout the day without having to upload data to a personal computer. More elaborate feedback and selfmonitoring was obtained by uploading the armband into the WMS account. When uploading was performed, participants could easily track physical activity, exercise, caloric intake, energy balance, and weight loss over the length of wear. Participants also had the option to create individualized target goals for all of the above variables and to generate meal plans and exercise routines to meet these goals.

\section{Statistical analysis}

Differences between the four study arms in the two primary endpoints will be tested according to the intention-to-treat philosophy. All randomized participants will be analyzed according to their group assignment at randomization, regardless of adherence to the intervention. The primary comparison is between the SWA-alone group and the GWL and standard care groups and between the GWL group with and without the armband. These are the preplanned comparisons. Secondary, tertiary, and exploratory analyses will focus on the secondary endpoints and subgroups, and findings will be interpreted cautiously. All analyses will take into account prespecified covariates, including age, gender, BMI, race, education, percentage of armband wearing time (ie, for SWA-alone and GWL + SWA groups), and baseline values of outcome measures. Analyses of continuous outcome measures will be based on analysis of covariance (ANCOVA) models of 9-month change scores since baseline, and treatment effects will be summarized as least squares adjusted means. ${ }^{35}$ We will also use linear mixed models to test the continuous outcome variables over time to increase statistical power. Analysis of binary outcomes will be based on logistic regression, and analyses of 
ordered polytomous outcomes will be based on ordered logit proportional-odds models. ${ }^{36}$ The potential effects of missing data will be explored under various models for nonignorable missing data mechanisms and through multiple imputation models under ignorable missing data assumptions. ${ }^{37}$

Given the target enrollment of 50 participants per treatment condition, the study design yields $80 \%$ power to detect an effect size of 0.62 (assuming $\alpha=0.025$ ) for weight loss and waist circumference reduction. Under $40 \%$ attrition, the study design will have $80 \%$ power to detect an effect size of 0.81 (assuming $\alpha=0.025$ ) for weight loss and waist circumference reduction. If we assume a standard deviation of $\sim 7.0$ for the baseline follow-up differences for two outcome measures of interest, we will have $80 \%$ power to detect a $0.5-\mathrm{kg}$ difference in weight loss and a $0.6-\mathrm{cm}$ difference in waist size reduction between any two of the study groups. These values are within the precision of our measures.

\section{Conclusion}

The LEAN study will evaluate the effectiveness of four approaches to enhance weight loss and waist circumference reduction over a 9-month period in sedentary and overweight or obese adults. The study is adequately powered to evaluate the primary outcomes, weight loss and waist circumference. The focus of this study is to evaluate the efficacy of providing real-time feedback on energy balance as part of a weight reduction program and to evaluate whether this approach enhances standard weight loss techniques. It should be noted that the overweight and obese participants in this study were volunteers and, as such, may be different (eg, psychologically or motivationally) from other community-dwelling overweight and obese individuals. Therefore, results from this study need to be interpreted with caution.

As suggested by research, individuals who use selfmonitoring strategies (ie, frequent weight checks, monitoring physical activity, and monitoring food intake) experience improved weight loss. ${ }^{12,38,39}$ Long-term weight management success depends on the adoption of healthy lifestyle strategies that balance energy expenditure and energy intake over time. Innovative approaches targeting real-time feedback and energy balance self-monitoring have begun to emerge. With proper interventions, these strategies may affect the current obesity epidemic and therefore improve the United States' health profile.

\section{Acknowledgments}

We thank the study participants for their dedication to advancing science. We thank the University of South Carolina student researchers Deidre Burch, Katelyn Tambellini, and Mia Taylor for their dedication to participant recruitment and retention, and thank Dr Rebecca A Meriwether for her guidance and advice throughout the study. We also thank the University of South Carolina's Clinical Exercise Research Director, Patrick Crowley. Without his assistance, participant recruitment and data collection would not have been possible.

\section{Disclosure}

The authors report no conflicts of interest in this work, meaning that the authors do not receive monetary or professional incentives through the promotion of the SenseWear Armband. This study was funded by an unrestricted research grant provided by BodyMedia, which means that BodyMedia did not have primary influence upon the research performed and did not make the grant conditional upon study outcomes. This trial was registered at www.clinicaltrials.gov (No. NCT00957008).

\section{References}

1. Flegal KM, Carroll MD, Ogden CL, Curtin LR. Prevalence and trends in obesity among US adults, 1999-2008. JAMA. 2010;303(3): 235-241.

2. Field AE, Coakley EH, Must A, et al. Impact of overweight on the risk of developing common chronic diseases during a 10-year period. Arch Intern Med. 2001;161(13):1581-1586.

3. Must A, Spadano J, Coakley EH, Field AE, Colditz G, Dietz WH. The disease burden associated with overweight and obesity. JAMA. 1999; 282(16):1523-1529.

4. Pan SY, Johnson KC, Ugnat AM, Wen SW, Mao Y; Canadian Cancer Registries Epidemiology Research Group. Association of obesity and cancer risk in Canada. Am J Epidemiol. 2004;159(3):259-268.

5. Finkelstein EA, Trogdon JG, Cohen JW, Dietz W. Annual medical spending attributable to obesity: payer-and service-specific estimates. Health Aff (Millwood). 2009;28(5):w822-w831.

6. Ash S, Reeves M, Bauer J, et al. A randomised control trial comparing lifestyle groups, individual counselling and written information in the management of weight and health outcomes over 12 months. Int J Obes (Lond). 2006;30(10):1557-1564.

7. Sharma M. Behavioural interventions for preventing and treating obesity in adults. Obes Rev. 2007;8(5):441-449.

8. Wing RR. Behavioral weight control. In: Wadden TA, Stunkard AJ, editors. Handbook of Obesity Treatment. New York: Guilford Press; 2002:301-316.

9. Bravata DM, Smith-Spangler C, Sundaram V, et al. Using pedometers to increase physical activity and improve health: a systematic review. JAMA. 2007;298(19):2296-2304.

10. Richardson CR, Newton TL, Abraham JJ, Sen A, Jimbo M, Swartz AM. A meta-analysis of pedometer-based walking interventions and weight loss. Ann Fam Med. 2008;6(1):69-77.

11. Baker RC, Kirschenbaum DS. Self-monitoring may be necessary for successful weight control. Behav Ther. 1993;24(3):377-394.

12. Wadden TA. The treatment of obesity: an overview. In: Stunkard AJ, Wadden TA, editors. Obesity: Theory and Therapy. New York: Raven Press; 1993:197-217.

13. Fruin ML, Rankin JW. Validity of a multi-sensor armband in estimating rest and exercise energy expenditure. Med Sci Sports Exerc. 2004; 36(6):1063-1069. 
14. Malavolti M, Pietrobelli A, Dugoni M, et al. A new device for measuring resting energy expenditure (REE) in healthy subjects. Nutr Metab Cardiovasc Dis. 2007;17(5):338-343.

15. Papazoglou D, Augello G, Tagliaferri M, et al. Evaluation of a multisensor armband in estimating energy expenditure in obese individuals. Obesity (Silver Spring). 2006;14(12):2217-2223.

16. Jakicic JM, Marcus M, Gallagher KI, et al. Evaluation of the SenseWear Pro Armband to assess energy expenditure during exercise. $\mathrm{Med} \mathrm{Sci}$ Sports Exerc. 2004;36(5):897-904.

17. St-Onge M, Mignault D, Allison DB, Rabasa-Lhoret R. Evaluation of a portable device to measure daily energy expenditure in free-living adults. Am J Clin Nutr. 2007;85(3):742-749.

18. Welk GJ, McClain JJ, Eisenmann JC, Wickel EE. Field validation of the MTI Actigraph and BodyMedia armband monitor using the IDEEA monitor. Obesity (Silver Spring). 2007;15(4):918-928.

19. Polzien KM, Jakicic JM, Tate DF, Otto AD. The efficacy of a technology-based system in a short-term behavioral weight loss intervention. Obesity (Silver Spring). 2007;15(4):825-830.

20. MyPyramid.gov. Available from: http://www.mypyramid.gov/. Accessed Jan 15, 2010.

21. Chobanian AV, Bakris GL, Black HR, et al. The seventh report of the Joint National Committee on Prevention, Detection, Evaluation, and Treatment of High Blood Pressure: the JNC 7 report. JAMA. 2003 289(19):2560-2572.

22. ACSM's Guidelines for Exercise Testing and Prescription. 8th ed. Baltimore (MD): Lippincott Williams \& Wilkins; 2010.

23. Rodriguez G, Moreno LA, Blay MG, et al. Body fat measurement in adolescents: comparison of skinfold thickness equations with dual-energy X-ray absorptiometry. Eur J Clin Nutr. 2005;59(10):1158-1166.

24. Zhang K, Werner P, Sun M, Pi-Sunyer FX, Boozer CN. Measurement of human daily physical activity. Obes Res. 2003;11(1):33-40.

25. Zhang K, Pi-Sunyer FX, Boozer CN. Improving energy expenditure estimation for physical activity. Med Sci Sports Exerc. 2004;36(5): 883-889.

26. Blair SN, Dunn AL, Marcus BH, Carpenter RA, Jaret P. Active Living Every Day: 20 Weeks to Lifelong Vitality. Champaign (IL): Human Kinetics; 2001.
27. Carpenter RA, Finley CF. Healthy Eating Every Day. Champaign (IL) Human Kinetics; 2005.

28. Bandura A. Social Foundations of Thought and Action: A Social Cognitive Theory. Englewood Cliffs (NJ): Prentice-Hall; 1986.

29. Prochaska JO, Norcross JC, DiClemente CC. Changing for Good: A Revolutionary Six-Stage Program for Overcoming Bad Habits and Moving Your Life Positively Forward. New York: Avon Book Inc; 1994.

30. Glanz K, Rimer BK, Lewis FM. Health Behavior and Health Education: Theory, Research, and Practice. San Francisco (CA): John Wiley and Sons; 2002.

31. Prochaska JO, Velicer WF. The transtheoretical model of health behavior change. Am J Health Promot. 1997;12(1):38-48.

32. Carpenter RA, Finley C, Barlow CE. Pilot test of a behavioral skill building intervention to improve overall diet quality. J Nutr Educ Behav. 2004;36(1):20-24.

33. Dunn AL, Marcus BH, Kampert JB, Garcia ME, Kohl HW 3rd, Blair SN Reduction in cardiovascular disease risk factors: 6-month results from Project Active. Prev Med. 1997;26(6):883-892.

34. Kohl HW 3rd, Dunn AL, Marcus BH, Blair SN. A randomized trial of physical activity interventions: design and baseline data from project active. Med Sci Sports Exerc. 1998;30(2):275-283.

35. Fleiss JL. The Design and Analysis of Clinical Experiments. New York: John Wiley and Sons; 1986.

36. Collet D. Modeling Binary Data. New York: Chapman and Hall; 1991.

37. Little RJA, Rubin DB. Statistical Analysis with Missing Data. New York: John Wiley and Sons; 2002.

38. Boutelle KN, Kirschenbaum DS. Further support for consistent selfmonitoring as a vital component of successful weight control. Obes Res. 1998;6(3):219-224.

39. Butryn ML, Phelan S, Hill JO, Wing RR. Consistent self-monitoring of weight: a key component of successful weight loss maintenance. Obesity (Silver Spring). 2007;15(12):3091-3096.

\section{Publish your work in this journal}

Diabetes, Metabolic Syndrome and Obesity: Targets and Therapy is an international, peer-reviewed open-access journal committed to the rapid publication of the latest laboratory and clinical findings in the fields of diabetes, metabolic syndrome and obesity research. Original research, review, case reports, hypothesis formation, expert opinion and commentaries are all considered for publication. The manuscript management system is completely online and includes a very quick and fair peer-review system, which is all easy to use. Visit http://www.dovepress.com/testimonials.php to read real quotes from published authors. 